\title{
The Construction and Implementation of Online Teaching Platform in Colleges and Universities
}

\author{
Hu Jianbo, Fan Tao*, Zhang Peng \\ Email address \\ jian_bo_h@163.com (Hu Jianbo), 491325356@qq.com (Fan Tao) \\ ${ }^{*}$ Corresponding author
}

School of Equipment Management and UAV Engineering, Air Force Engineering University, Xi'an, China

To cite this article:

Hu Jianbo, Fan Tao, Zhang Peng. The Construction and Implementation of Online Teaching Platform in Colleges and Universities. Science Innovation. Vol. 8, No. 5, 2020, pp. 139-143. doi: 10.11648/j.si.20200805.14

Received: September 4, 2020; Accepted: October 27, 2020; Published: November 4, 2020

\begin{abstract}
After the Spring Festival in 2020, the teaching work across the country has been greatly affected by the COVID-19 epidemic. How to solve the problem of "suspended class, ongoing learning" is in front of the teaching staff.Meanwhile, with the investment and construction in the field of education in China, informatization has been widely applied and can be used as a variety of online teaching tools.According to the actual needs of online teaching of "Introduction to UAV System" course, combined with the characteristics of this course, this paper first constructed the teaching platform of "DingTalk + WeChat + E-mail". At the same time, focusing on the teaching process of "online lesson preparation + online teaching + online homework + online test", the specific characteristics and detailed practices of pre-class preparation, classroom organization, after-class consolidation and unit test are expounded in depth.In the teaching organization, I organized online teaching meetings for many times, listened to students' opinions and Suggestions, and organized online examinations for students after the end of the chapter, and analyzed the test results. Finally, the author points out the problems in online teaching, such as insufficient accumulation, inadequate response and inadequate supervision, and puts forward some countermeasures and Suggestions.
\end{abstract}

Keywords: Online Teaching, Teaching Platform, Ding Talk, Countermeasures and Suggestions

\section{高校线上教学平台的构建与授课过程实施}

胡剑波, 樊涛", 张鹏

空军工程大学装备管理与无人机工程学院, 西安, 中国

\section{邮箱}

jian_bo_h@163.com（胡剑波），491325356@qq.com(樊涛)

摘要：2020年春节后, 全国的教学工作受到新冠疫情影响较大, 如何解决停课不停学问题, 摆在教学工作者面前。同 时，随着我国在教育领域的投资建设，信息化已经较为普遍应用，可作为线上教学工具多种多样。本文针对《无人机 系统概论》课程开展线上教学的实际需要, 结合该课程的特点, 本文首先构建了“钉钉+微信+电子邮件”的授课平台。 同时，聚焦“网上备课+网上授课+网上作业+网上测试”的授课过程，深入阐述了课前准备、课堂组织、课后巩固、单 元测试的具体特点和详细做法。最后, 指出了线上教学中存在的积累不足、应对不足和监管不足等问题, 并提出了对 策建议。

关键词: 线上教学, 授课平台, 钉钉, 对策建议 


\section{1. 引言}

2020年春节后, 全国受到新冠疫情的影响, 我国大、 中、小学的开学日期也一再推迟。教学工作在此情况下如 何开展, 摆在我们教育工作者面前。从教育部到各个学校 分别做出应对措施, 基本达成“停课不停学”的共识, 普遍 采用网络教学模式, 保证各项教学活动正常开展, 使疫情 对学生学习的影响降至最低[1-2]。对于高等教育的基础公 共类课程比较适合开展网上授课, 我校《无人机系统概论》 课程作为一门专业基础课程, 也是重点课程建设的一门 “双语”模改课程, 面向大二学员第二学期开设, 所以该课 程在疫情初期就确定要进行线上教学。《无人机系统概论》 这门课是学员在掌握了基础课程知识后, 开始学习专业课 程的第一门专业课程[3]。学员将通过这门课程系统地了解 本专业的主要研究对象和工作范围, 并开始认知其未来的 工作岗位。

近年来，随着我国在教育领域的投资建设，信息化 已经较为普遍应用, 可作为线上教学工具多种多样。线 上教学平台在多年实践探索中, 不断完善, 相关机制也 在不断补充发展, 这为我们实行线上教学提供多种可选 择平台实施授课。完全的线上教学与传统的信息化教学 有一定关联, 但实施难度和方式已经有了质的不同。如 何打造出一门高质量的线上课程, 我们做了积极的探索, 克服困难, 构建授课平台, 精心设计授课过程, 从而达 到我们的教学目标。

本文就如何䇥选线上教学平台工具, 构建此线上教学 平台优势, 如何组织实施教学活动, 结合实践过程进行相 关研究论述。阐述了课前准备、课堂组织、课后巩固、单 元测试的具体特点和详细做法 [3]。最后, 指出了线上教学 中存在的积累不足、应对不足和监管不足等问题, 并提出 了对策建议。

\section{2. 构建“钉钉+微信+电子邮件”的授课平台}

当下互联网授课已非常流行, 授课平台多样, 组织形 式各异, 在开展线上教学时要充分利用现代网络技术资源。 结合教员学员特点, 以及平台稳定易用性等因素, 我们要 构建出适合当前课程的授课平台。构建出的平台将打破传 统授课方式, 及教师在授课过程中扮演的角色, 学生在学 习过程中改变固有掌握知识的方法, 从而改变教学组织结 构和教学实施手段。

对于我们熟悉传统课堂授课的教员来说, 网络平台的 选择至关重要, 直接关系到线上教学该怎么实施、效果能 否达到预期、学员能否适应这种授课方式等诸多挑战的有 效破解。带着这些疑问和未知的挑战, 在教研室多次统筹 规划下, 我们提前预估了钉钉、雨课堂、学堂在线、腾讯 会议等诸多线上教学平台可能发生的网络拥堵、服务器故 障等问题, 通过对比物理网络资源、大型数据库资源和技 术服务能力, 决定采用阿里巴巴集团开发的“钉钉”软件为 线上主要教学平台, 微信、电子邮件等为辅。

钉钉（DingTalk）是阿里巴巴集团专为中国企业打造 的免费沟通和协同的多端平台, 提供PC版, Web版, Mac 版和手机版, 支持手机和电脑间文件互传, 功能强大, 性 能稳定 [4]。在线上教学中, 可使用“直播模式”进行直播授 课; 可使用“会议模式”进行互动讨论, 可借助“圈子”提前 上传MOOC视频。实践证明, “钉钉”非常适合组织开展网 上授课教学。在选择“钉钉”软件作为线上教学平台的同时, 我们还将滕讯会议、陕西省MOOC网站等作为辅助备份, 结合实际授课需要, 在开课前, 进行了适当的互联互播测 试。当然, 我们还采用了大家熟悉的软件工具, 微信和电 子邮件, 组建了课程微信群、作业电子邮件群和测试综合 群。课程微信群, 用于提前发布课程信息, 进行知识点答 疑, 学习交流等[5]。作业电子邮件群, 用于作业布置、作 业递交、作业批改和作业交流[6]。测试综合群, 用于教员 在统一时间发布考题和密码、学生限时作答和提交。
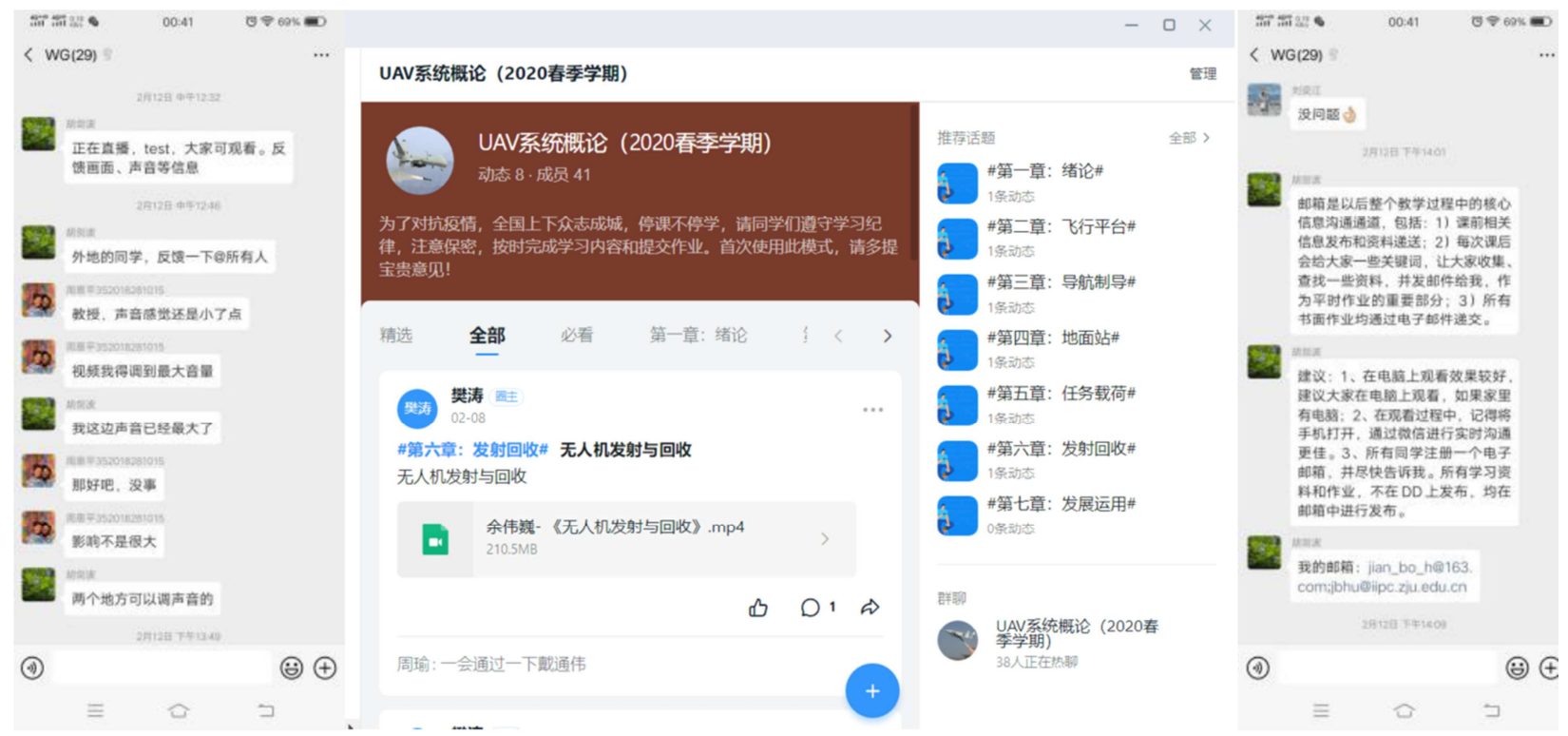

图1 授课平台, 钉钉+微信+电子邮件。 
前期我们已录制了 9 次慕课视频如表 1 所示, 上传到钉 钉的圈子, 供学员上课前预先学习使用。在圈子中设置相 关问题, 让学员预习完视频后, 回答问题, 以此来掌握学 员学习情况。

表1 网络授课MOOC视频。

\begin{tabular}{ll}
\hline 序号 & MOOC视频内容 \\
\hline 1 & 无人机系统组成与发展 \\
2 & 无人机飞行平台 \\
3 & 无人机导航与控制 \\
4 & 无人机任务规划与指挥控制 \\
5 & 无人机地面站与测控链路系统 \\
6 & 无人机发射与回收 \\
7 & 无人机任务载荷 \\
8 & 典型无人机系统 \\
9 & 无人机作战运用典型案例 \\
\hline
\end{tabular}

\section{3. 聚焦“网上备课+网上授课+网上测试”的授课 过程}

我们从 2 月 18 日正式开始网络直播授课, 每周二, 周 五上午3、4节上课, 网上授课共30学时。我们聚焦“网上 备课+网上授课+网上测试”的授课过程, 重点抓好课前准 备、课堂组织、课后巩固, 并适时开展单元测试和教学联 席会议, 尽最大可能使学员更好地掌握所学知识、提高学 习效率。我们的具体做法如下:

课前准备。与传统授课相比, 线上授课课前准备都是 在网上进行的。为了在课前准备好满足线上教学需要的教 学课件、教学视频和动态展示素材, 除了传统的教案编写、 课件制作、作业批改等课前准备工作之外，我们既要利用 诸如文献资料、影像作品、图片素材等可获取的网上教学 资源来充实教学内容, 又要利用自行开发的模拟动画、数 值仿真等辅助教学资源来充实教学内容[7]。从这个意义上 讲, 网上授课给课前准备带来了前所未有的工作强度、难 度、复杂度、精细度和灵活度, 在上一次课前, 我们要花 费 2 天左右时间完成这些准备。同时，考虑到本门课程采 用初级双语教学模式, 相关的资料还要做到中英文对照。 所有这一切都彻底打破了传统的课前准备模式, 其内涵更 加丰富，必须花费我们更多的精力和时间。

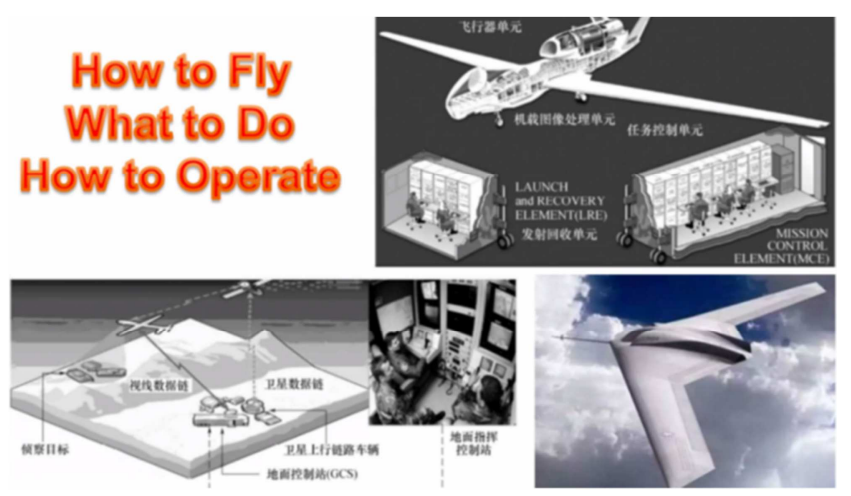

图2 课前准备, 教案+课件+数值模拟 + 视频 $+\ldots \ldots$. 。
(二) 课堂组织。与传统授课相比, 网络课堂的组织 必须做到专业和专心 [8]。教员通过直播方式进行知识传授、 作业讲评或集中答疑, 只存在通过课件的视听感受, 没有 通过身体语言、情感表达的情景展示。这就需要授课教员 必须具备专业的线上教学技能 [9], 包括概念阐述要明确清 晰、知识点传授要环环相扣、原理讲解要难易适中、互动 环节要有问有答、情景模拟要身临其境, 以确保教学效果。 同时, 线上教学还需要学员专心, 必须充分考虑视听效果、 学员反应能力、网络延迟、网络中断等可能的影响因素, 专心地编排教学素材、设计互动环节和现场提问环节, 以 确保授课质量。在授课过程中, 我们添加适当的互动, 学 员在观看直播中, 直接打出字幕回答问题, 这样及时掌握 了学员学习情况, 同时又可以避免因缺少身临其境学员听 课过程中走神, 注意力不集中的情况。在阶段性结束时, 我们组织了学员分组讨论, 每个小组分别设置不同题目, 学员提前搜集资料, 然后参与到直播中, 从而巩固阶段性 知识点。

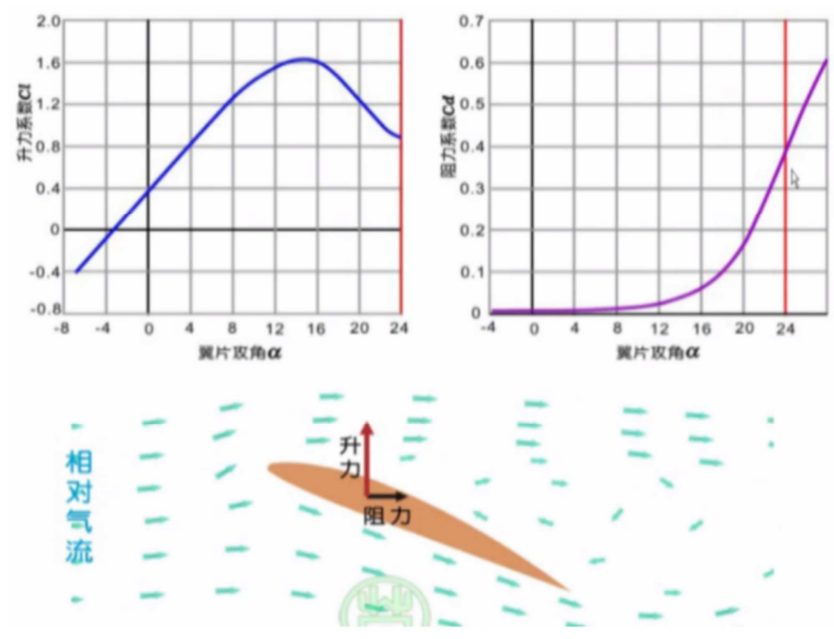

图3 课堂组织, 专业+专心......+

（三）课后巩固。本门课程是一门双语课程, 也是专 业基础课程, 涉及知识面广, 需要学员课后搜集补充相关 的专业知识点, 同时阅读相关的英文资料。在每次课后, 我们会列出所学内容的知识点, 并浓缩成几个中英文对照 的关键词 (如, 控制 (control)、飞行控制 (flight control)、 编队飞行（formation control）），供学员在网上搜集相关 的学习资料, 深入思考感兴趣的专业或者学术问题, 巩固 知识点, 扩展知识面, 提升专业英文阅读能力 [10-11]。每 次作业都布置翻译作业, 翻译内容为课堂中知识点对应的 英文介绍, 学员完成翻译作业, 既是对专业英文水平的提 升, 又可巩固课堂知识点。同时, 鼓励学员在课后自己动 手编制小程序、制作小模型（如，编制飞机爬升过程演示 小软件、制作纸质翼型) 来验证所学基础知识, 进行亲身 体验。 


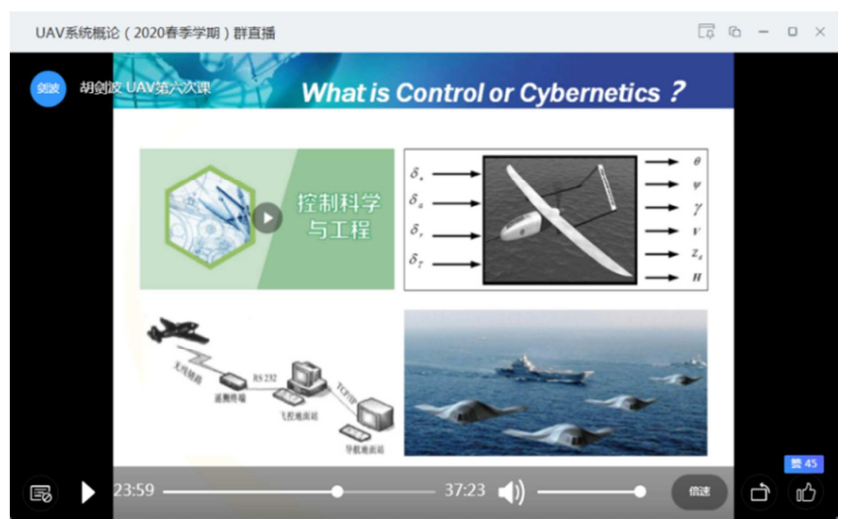

图4 课后巩固, 知识点+关键词。

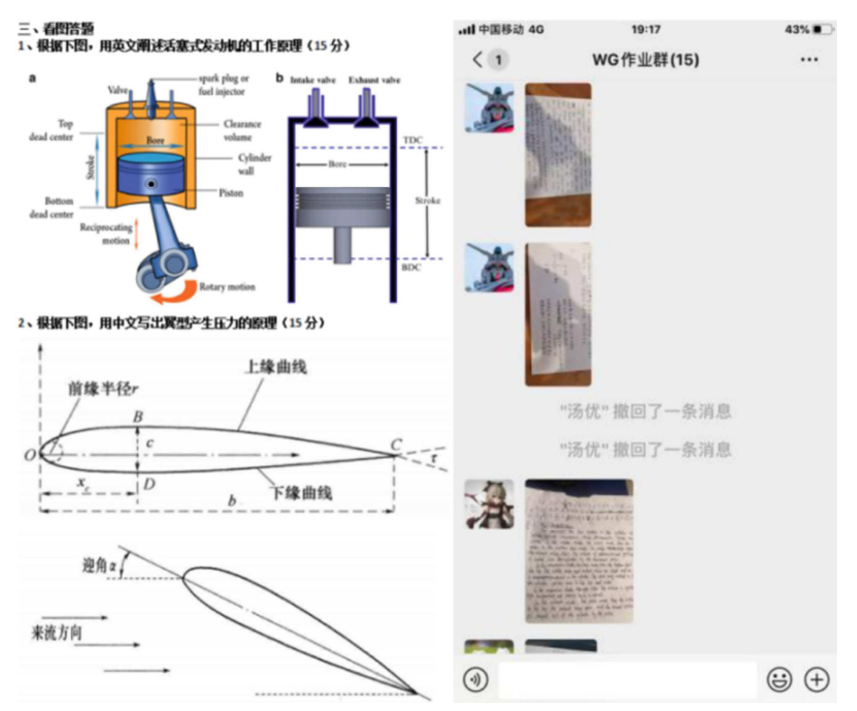

图5《无人机系统概论》课程进行的网上测试。

单元测试。针对网上授课中可能存在诸如概念讲授缺少 心智交流、情景展示缺少现场感受、原理传授缺少互动体验
等不足的问题, 为了及时掌握学员对本门课程的知识掌握程 度, 及时发现了诸如对概念模糊不清、对原理一知半解、对 组成构造张冠李戴等问题, 我们先后组织了 3 次测试, 以便 在返校后组织的集中串讲中, 进行逐个梳理和仔细讲解, 更 好地破解线上教学的固有矛盾, 做到线上线下的有机统一。 针对线上教学的特点, 测试题以判断题、选择题和图示题为 主, 以考查学员对基础知识、工作原理的理解和掌握程度。

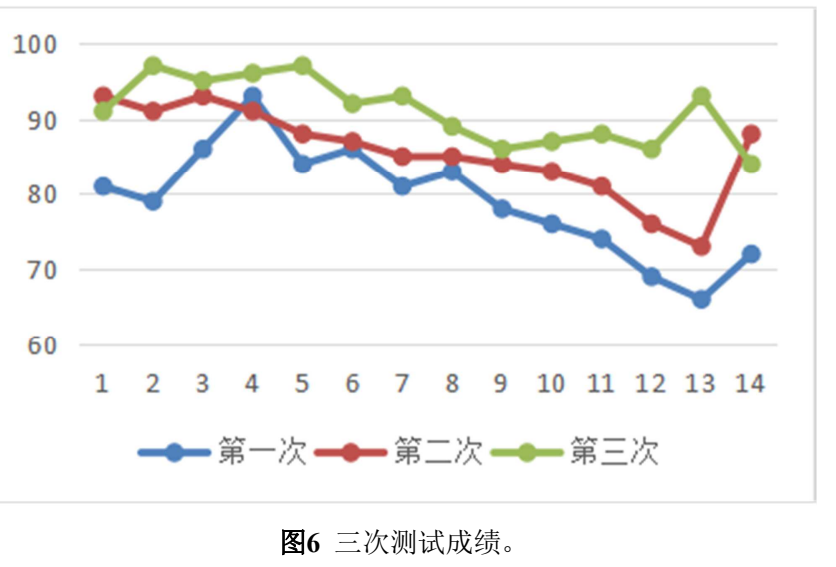

测试成绩如图6所示, 横坐标为14名学员, 纵坐标为 考试成绩, 共进行了三次考核, 均采用百分制, 考试结果 中所有学员成绩都高于 60 分, 低于 100 分。然后用相同颜 色线条将三次考试成绩分别连接, 第一次成绩为蓝色, 第 二次成绩为红色, 第三次成绩为绿色。分析可发现学员第 一次成绩较低, 第二次有所提升, 第三次最好。说明学员 在初次接触全部线上教学还不太适应, 在后期逐步适应线 上教学的组织方式。

教学联席会议。在授课的同时, 我们也多次通过腾讯 视频会议组织了教学联席会, 及时掌握学员学习动态, 对 学员反馈的问题, 我们在教学实施中不断改进。学员提出 主要问题及回复内容表2所示。

表2 教学联席会问题及答复。

\begin{tabular}{|c|c|c|}
\hline 序号 & 学员反馈问题 & 问题答复 \\
\hline 1 & 希望课程中增加实际案例 & \multirow{4}{*}{$\begin{array}{l}\text { 平时上课中我们也会加入国外先进无人机及作战案例, 丰富课堂, 增加课堂的趣味性。 } \\
\text { 这门课作为初级双语课, 在上课中的课件, 课后作业中会体现, 对学员的要求不高, 大 } \\
\text { 家不要有心理负担, 都有个适应过程, 这也是对大家专业英语有很大帮助。 } \\
\text { 学习这门课, 需要我们有无人机系统的概念, 按照机-站-链组成, 我们逐步来学习相关 } \\
\text { 知识, 这门课是一门专业基础课, 承上启下, 为后续的专业课奠定良好基础。 } \\
\text { 通过互联网查找专业资料, 这是长期经验的积累, 后续我们将在上课过程中告诉大家哪查等, 也望大家动手自己找相资料。 } \\
\text { 过互联网, 查什么, 怎么查, }\end{array}$} \\
\hline 2 & 作为双语课, 对我们的英语要求高不高? & \\
\hline 3 & $\begin{array}{l}\text { 这门课需要我们掌握哪些知识, 以及对后续 } \\
\text { 的专业课有什么帮助? }\end{array}$ & \\
\hline 4 & 如何高效的通过互联网查找相关资料? & \\
\hline
\end{tabular}

学生提出的问题涉及教学安排、学习方法、学习资源、 双语教学、专业状况等方面的多个感兴趣的问题, 14 人每 人都进行了充分的发言。

针对学员、教研室领导、学员队干部提出的问题或者 建议我们将在后续上课中不断提高, 不断改进主要措施如 下:

1)课堂中突出重难点, 线上多和学员互动;

2)课后对学员的作业情况及时反馈, 掌握学员学习情 况;

3)在教学中注重实践案例与知识点相结合 [12]。

\section{4. 主要问题和建议}

通过线上教学平台的构建, 《无人机系统概论》课程 在线上教学部分圆满完成。但是, 针对本门课程构建的线 上教学平台, 也存在着一些问题:

(一) 线上教学的积累不足: 线上教学需要丰富的教 学资源, 需长期积累, 本门课虽然每次授课前两天我们都 做了精心准备, 但是授课过程中仍然发现积累不足 $[9,13]$ 。

(二) 网络意外的应对不足：由于是网路授课, 全国 使用网络资源进行授课的用户较多, 尽管我们已经提前对 
网络中断、网络延迟等情况进行了预估, 但是在组织切换 备用平台时，花费较多时间。

(三) 网络听课的监管不足: 与传统教学相比, 学员 上课很有带入感, 教员可以实时看到学员的学习状态。但 在线上教学中, 教员很难兼顾教学与所有学员状态, 对此, 我们必须高度重视。

针对上述问题, 我们建议:

（一）注重网络资源的日常积累：任课教员要在日常 业务工作中, 积累相关的网上教学资源, 及时下载和保存, 包括网址名称、作者基本信息、文献资料基本信息等。有 了这些积累, 后续的线上教学将十分受益 $[2,14]$ 。

(二) 加强线上教学的内涵建设: 网络课程必须依赖 于网络, 在网络中开发, 在网络中使用。任课教员要针对 线上教学的特点, 深入研究课程的网课内涵, 包括课件、 视频、经典著作、动画模拟、算法等。依托这些内涵建设 成果, 可以大大减缓网络意外对于线上教学的影响。

(三) 增加线上授课平台互动: 这是需要我们深入思 考并加以解决的问题。我们可以在线上教学的过程中, 适 时加入现场提问、限时回复等方式来监管整个学习过程, 也可以采用视频随机抽取的方法来查看听课情况[15-16]。

\section{5.小结}

本文针对《无人机系统概论》课程开展线上教学的实 际需要, 结合该课程的特点, 构建了“钉钉+微信+电子邮 件”的授课平台。同时, 聚焦“网上备课+网上授课+网上作 业+网上测试”的授课过程, 深入阐述了课前准备、课堂组 织、课后巩固、单元测试的具体特点和详细做法。最后总 结了使用该平台过程中遇到的问题, 并并提出了对策建议。 同时, 指出了线上教学中存在的积累不足、应对不足和监 管不足等问题，希望本文实践探索对实施线上教学人员能 提供可用参考。

\section{参考文献}

[1] 吕明旭,许文君.高校疫情危机中的辅导员角色 [J].济南职业 学院学报,2014(04):69-71.
[2] 沈 震. 疫情防控下高校思想政治理论课线上教学策略 [J]. 思想理论教育导刊, 2020（3）：15－19。

[3] 陈霖周廷,刘占超.基于项目导向的《无人机系统》课程教学 改革实践[J].教育现代化,2018,5(29):43-44.

[4] 张博. 基于移动端的听评课APP 设计与开发 $[D]$.上海师范 大学,2017.

[5] 邓境, 蒋神, 雷寒. 基于微信公众平台的教学模式构建与 实施——以"医事法律讲堂"辅助《卫生法》教学为例 $[\mathrm{J}]$. 中 国教育信息化, 2017, 409(22):57-59+64.

[6] 徐达勋.基于MOOC教学的高职教学模式研究 [J].教育教学 论坛,2020(31):379-380.

[7] 仇善梁,房翠.基于阿里钉钉的班级管理应用探索与实践 [J]. 河北软件职业技术学院学报,2018,20(01):1-3+6.

[8] 白凡凡. 浙江大学网络授课系统的设计和实现[D].浙江大 学,2002.

[9] 余频. 会计实务虚拟课堂的构建研究 [D]. 南京师范大 学, 2008 .

[10] 黄雷.E一learning 与英语自主学习 $[\mathrm{J}]$. 吉林省教育学院学 报,2006(06):59-61.

[11] 王风辉.疫情防控期间高职线上教学调查研究 $[\mathrm{J}]$.职业教育 (下旬刊),2020,19(05):58-64.

[12] Nikolaos Patelis. Distance learning for vascular surgeons in the era of a pandemic $[\mathrm{J}]$. Journal of Vascular Surgery,2020,72(1).

[13] 邰丽. 新冠疫情下线上教学的不足与改进 [J]. 价值工 程,2020,39(21):7-8.

[14] 唐源,刘明哲,李英毅, 吴旭,欧鸥.抗疫期间高校课程在线教 学方法探讨与实践 [J].计算机教育,2020(08):23-27.

[15] 席晓萌. 线上教学的探索与实践 [N]. 中国建设 报,2020-07-27(003).

[16] 张双双,杨洪涛,张义龙. 疫情期间高校线上网络教学模式探 讨 [J].中国现代教育装备,2020(11):11-13. 